\title{
DEBATES
}

\section{Notas sobre a reforma do setor elétrico de Dilma Rousseff e a dimensão coordenativa das capacidades estatais}

\author{
Notes on Dilma Rousseff's reform of the power sector and the \\ coordinating dimension of state capacities
}

\section{Andrea Oliveira Ribeiro \\ Roberta Rodrigues Marques da Silva}

\section{Resumo}

Esse artigo analisa as mudanças institucionais no setor elétrico levadas a cabo pelo governo Dilma Rousseff, relacionando-as à crise política mais ampla que permeou o seu segundo mandato, levando à sua derrubada em 2016. Mobilizando a literatura sobre capacidades estatais, buscamos avançar na discussão sobre as capacidades de coordenação como elemento explicativo para a crise. Rousseff buscou retomar o intervencionismo estatal no setor elétrico, pretendendo deslocar o protagonismo adquirido ao longo dos anos anteriores pelo empresariado privado, sobretudo estrangeiro. Essa reforma, porém, foi amplamente criticada, inclusive pelo empresariado beneficiado pela redução das tarifas de eletricidade. Nossa hipótese é que os problemas na dimensão coordenativa das capacidades estatais levaram ao enfraquecimento da coalizão governista nascida em 2003.

\section{Palavras-chave}

Setor Elétrico; Capacidades Estatais; Coordenação.

\section{Abstract}

This paper aims to analyze the institutional changes in the electric sector carried out by Dilma Rousseff's government, relating them to the wider political crisis that permeated its second term, leading to its overthrown in 2016. Mobilizing the literature on state capabilities, we seek to advance the discussion on coordination capacities as an explanatory element for the crisis. Rousseff sought to retake state intervention in the electric sector, intending to displace the protagonism acquired over the previous years by private entrepreneurs, especially foreigners. This reform, however, was widely criticized, even by business groups benefiting from the reduction of electricity tariffs. Our hypothesis is that the problems in the coordinative dimension of state capacities led to the weakening of the ruling coalition born in 2003.

\section{Keywords}

Electric Sector; State Capabilities; Coordination. 


\section{Introdução}

A deposição de Dilma Rousseff, em 2016, e a agenda de reformas adotada por Michel Temer se apresentam enquanto desafio empírico para a compreensão das capacidades estatais no Brasil. Se até a reeleição de Rousseff, em 2014, havia certa convergência na literatura a respeito da retomada das capacidades estatais para a promoção de uma agenda social-desenvolvimentista, caracterizada pela ampliação das políticas públicas voltadas para o incentivo à produção e à inclusão social, os eventos posteriores revelaram que o Estado também é capaz de coordenar as ações de atores políticos e empresariais em prol do desmonte da capacidade de intervenção estatal. A rápida aprovação da proposta de emenda constitucional que limita os gastos e investimentos públicos por vinte anos e a aprovação da reforma trabalhista indicam, respectivamente, a limitação, por iniciativa do próprio governo, da capacidade de implementação de políticas públicas e o menor intervencionismo estatal nas relaçôes empregador-trabalhador, em franco favor aos interesses empresariais. $\mathrm{Na}$ mesma linha, a retomada da proposta de privatização da Eletrobras, empresa estatal fortemente atuante no setor elétrico brasileiro que havia sido mobilizada como instituição-chave para a redução das tarifas de eletricidade em 2013, durante o governo Dilma, também revela a radical mudança na orientação até então prevalecente de fortalecimento do intervencionismo estatal na economia.

Neste artigo, temos como objetivo analisar as mudanças institucionais no setor elétrico levadas a cabo pelo governo Rousseff no contexto da crise política mais ampla que permeou o seu segundo mandato e que culminou na sua derrubada em 2016. Mobilizando a literatura sobre capacidades estatais, buscamos avançar na discussão sobre as capacidades de coordenação como elemento explicativo para a crise. Rousseff buscou retomar o intervencionismo estatal no setor elétrico, pretendendo deslocar o protagonismo adquirido ao longo dos anos anteriores pelo empresariado privado, sobretudo estrangeiro. Essa reforma, porém, foi amplamente criticada, inclusive pelo empresariado beneficiado pela redução das tarifas de eletricidade. Nossa hipótese é que os problemas na dimensão coordenativa das capacidades estatais, que levaram ao enfraquecimento da coalizão governista e à destituição de Rousseff em 2016, perpassaram a conduçáo das mudanças implementadas por meio da Medida Provisória (MP) 579/2012.

O artigo está organizado da seguinte forma: na primeira seção, faremos uma revisão da literatura sobre capacidades estatais, enfatizando sua dimensão sociopolítica. Em seguida, construiremos uma narrativa sobre as reformas 
70 | Andrea Oliveira Ribeiro e Roberta Rodrigues Marques da Silva

institucionais no setor elétrico desde a década de 1990, de modo a identificar os interesses afetados pela MP 579. Na terceira seção, faremos uma análise exploratória sobre a crise política que levou à derrubada da presidenta eleita. Comentários finais encerram o artigo.

\section{A dimensão da coordenação sociopolitica na literatura sobre capacidades estatais}

No bojo do debate sobre a produção de políticas públicas no Brasil desenvolveu-se nos últimos anos uma fértil literatura em ciência política preocupada com o "Estado em ação" (JOBERT e MULLER, 1987) ou com os impactos da ação estatal e das relaçóes Estado-sociedade sobre a qualidade da democracia (GOMIDE e PIRES, 2014; GOMIDE, 2016). Essa reflexão foi estimulada a partir dos anos 1990 pelas experiências de reforma estatal, que contemplavam a adoção de políticas de redução do gasto público e privatização, amparadas pelo surgimento de novas formas de pensar o papel dos governos sob o imperativo do ajuste fiscal e a revisão do grau de intervencionismo estatal possível na economia (SOUZA, 2006).

As análises desenvolvidas sob a perspectiva da ciência política buscavam desvelar o modo como as agendas públicas são constituídas, quais temas importam coletivamente, e quais atores detêm poder de escolha, definição e execução. As políticas (no sentido de policies) poderiam então ser entendidas como açóes implementadas pelo Estado e pelas autoridades governamentais em condiçôes específicas, resultado de um processo complexo que envolve vários centros dinâmicos na luta pela distribuição de recursos, que refletem os interesses conflitantes dos diversos atores em pugna (MARQUES, 2013).

Sob influência do neoinstitucionalismo, produziu-se um giro teórico importante que trouxe as instituiçôes para o centro da análise e deslocou a tradicional ênfase sobre as etapas da formulação (desenho) e decisão (votação ou deliberação) dos estudos pluralistas e elitistas para ocupar-se também da etapa de implementação (execução). Essa virada teórica permitiu a complexificação das análises ao incorporar os atores estatais (parlamentares e burocratas) e não-estatais (organizações e grupos de interesse), suas ideias e interesses, e reconhecer a relativa autonomia das agências e seus funcionários no processo de produção de políticas diante das pressões sociais. Dessa forma, a construção de agendas e de estratégias defendidas pelos diversos atores em disputa, assim como os resultados, passa a ser entendida como fruto da interação e coordenação entre agentes estatais e não estatais em ambientes institucionais específicos. 
Esse novo enquadramento analítico colocou a questão de como e em que medida os Estados têm capacidade para garantir a implementação de políticas. Nessa direção, a agenda de pesquisa inaugurada na década de 1980 com o lançamento da compilação Bringing the State Back In (EVANS, RUESCHMEYER e SCKOCPOL, 1985), pode ser considerada um marco do movimento de recuperação do Estado como categoria analítica. Esses trabalhos propunham que a compreensão do alcance da ação estatal deveria considerar dois elementos centrais: a autonomia estatal ${ }^{1}$ e as capacidades estatais ${ }^{2}$, ambas necessários à promoção de estratégias de desenvolvimento econômico (SKOCPOL, 1985). As capacidades extrativa e de centralização política estariam atreladas à força dos Estados para promoverem mudanças institucionais (TILLY, 1996). Por outro lado, a combinação entre autonomia e capacidade estatal implicaria em refletir sobre os limites entre poder despótico e poder infraestrutural, este último definido como o poder de "[...] penetrar de verdade a sociedade e implementar de modo logístico decisóes políticas através de seu domínio" (MANN, 1984, p.113).

Ao sugerir que é possível distinguir entre situações em que o Estado goza de "extrema autonomia" - implementação desde cima - ou de "relativa autonomia" necessidade de coordenar interesses institucionalmente, Skocpol (1985, p. 9 e 12) se aproxima da distinção entre poder despótico e infraestrutural de Mann. Essa distinção indica que pode haver diferenças significativas nos graus de legitimidade dos projetos de desenvolvimento de acordo com o tipo de regime político de um país, ao mesmo tempo que não atribui qualquer relação necessária entre projetos inclusivos e democracia.

Evans (1995) também admite que há barreiras à participação de múltiplos setores sociais em projetos de desenvolvimento. Seu conceito de "autonomia inserida" propóe que os aspectos de coesáo interburocrática e de conectividade com o capital industrial a priori podem ser definidos como excludentes por não prescindir de outros atores sociais, embora não exclua a possibilidade de coalizóes políticas mais amplas. Essas, contudo, exigem maior capacidade coordenativa para mediar interesses diversos

\footnotetext{
1 Autonomia estatal é a "[...] formulação e busca de objetivos [pelos Estados] que não são apenas reflexos das demandas ou interesses dos grupos sociais, classes ou sociedade" (SKOCPOL, 1985, p. 9, tradução nossa).

${ }^{2}$ As capacidades estatais estão relacionadas “[...] à implementação de objetivos públicos, especialmente sobre a oposição real ou potencial de grupos sociais poderosos ou em face de circunstâncias socioeconômicas recalcitrantes" (SKOCPOL, 1985, p. 9, tradução nossa).
} 
que poderiam se traduzir em obstáculo a projetos de desenvolvimento industrial e tecnológico, cujo tempo de maturação, muitas vezes, é diminuto. Autonomia estatal relativa parece indicar apenas que, guardadas as condiçóes de "normalidade institucional”, a presença de funcionários, burocratas e corpo técnico "comprometidos" com as tarefas de diagnosticar problemas coletivos e criar alternativas políticas para lidar com eles (poder infraestrutural) é necessária.

Seria preciso perguntar a quem serve a capacidade estatal, e se há um trade off necessário entre três importantes elementos: soberania estatal, desenvolvimento econômico e inclusão social (CENTENO, KOHLI e YASHAR, 2017). Ao abrir-se o questionamento sobre a qualidade dos resultados das açôes estatais, reconhece-se a importância de pensar as capacidades estatais como um conjunto de instrumentos e instituiçôes à disposição do Estado, mas também a necessidade de incorporar a essa análise o componente da coordenação política por oposição à noção de coordenação técnica baseada em instituições em funcionamento.

Essa literatura foi retomada por pesquisadores brasileiros no contexto da eleição de Lula, em 2002, que deu início a um período de maior intervencionismo estatal. Entretanto, o ineditismo da situação - ampliação da ação estatal na regulação dos mercados e garantias constitucionais democráticas - recolocava o problema da viabilidade de promover crescimento econômico e, simultaneamente, expandir a cidadania. Para os analistas brasileiros, a pergunta era se o Estado brasileiro seria "capaz" de combinar crescimento e cidadania, isto é, promover desenvolvimento inclusivo.

Pires e Gomide (2016), partindo de uma abordagem dos “arranjos institucionais", propóem que o conceito de capacidades estatais abarcaria duas dimensões. A capacidade técnico-administrativa, relacionada à presença de organizações com recursos humanos, tecnológicos e financeiros e à existência de mecanismos de coordenação intra e intergovernamental e estratégias de monitoramento que envolvem produção de informação e exigências de desempenho. E a dimensão política-relacional, associada às formas de interação burocrática, aos mecanismos de participação social e à atuação dos órgãos de controle.

A multiplicidade de atores e interesses que devem ser coordenados burocracias de diferentes níveis governamentais, parlamentares de diversos partidos, múltiplas organizaçóes da sociedade civil - torna o processo decisório mais complexo e moroso. De todo modo, é essa capacidade coordenativa, mais política do que técnica, que determina a capacidade de um Estado implementar uma política pública com sentido específico. 
No caso da análise das capacidades estatais aplicada ao setor elétrico brasileiro, além de considerar o arcabouço institucional herdado de anos anteriores a 2003 e aquele construído ao longo dos governos do PT, é preciso levar em conta os atores estatais e não estatais em disputa - a Agência Nacional de Energia Elétrica (ANEEL), o Ministério de Minas e Energia (MME), as empresas públicas, por um lado, e os atores privados (grupos de interesses, empresas nacionais e internacionais e sociedade civil) de outro, assim como identificar seus interesses e preferências.

A tentativa de relacionar o debate sobre capacidades estatais, tendo como referência a crise do setor energético iniciada em 2012, busca evidenciar que o simples estabelecimento de instâncias burocráticas de planejamento sob administração estatal não implica em resultados positivos se considerados aspectos redistributivos ou mesmo de produtividade. A existência de coalizóes de apoio ao governo é que determina a direção e a operacionalização das capacidades estatais. Isto é, defendemos que a autonomia estatal é relativa e dependente de uma coalizão de apoio.

O componente político é fundamental para a compreensão do desenho e dos resultados das reformas das instituições que regulamentam o setor elétrico desde os anos 1990, nos governos Cardoso, Lula e Rousseff. Estas reformas levaram a mudanças e inovações institucionais importantes, que não apenas refletiram interesses preexistentes, como também levaram à emergência de novos interesses e correlaçóes de forças políticas, alterando a capacidade de coordenação por parte do Estado.

\section{Reformas institucionais no setor elétrico brasileiro}

As reformas institucionais no setor elétrico brasileiro acompanham as mudanças mais amplas nas coalizões políticas e nas estratégias de desenvolvimento adotadas no Brasil ao longo da trajetória histórica ${ }^{3}$. A formação do setor elétrico nacional, caracterizado pela criação de grandes empresas estatais de geração e pela progressiva interconexão do sistema elétrico nacional, deve ser compreendida no contexto da centralização das atividades do Estado na condução da agenda de desenvolvimento econômico, buscando, assim, ampliar a capacidade de planejamento e de penetração do poder estatal pelo território nacional. O acesso à energia elétrica é fundamental para o desenvolvimento de qualquer atividade industrial (LEME, 2014) e, ademais, é indicador básico na mensuração do nível de desenvolvimento social de

\footnotetext{
${ }^{3}$ Para uma discussão mais detalhada sobre o tema, ver Leme (2014).
} 
74 | Andrea Oliveira Ribeiro e Roberta Rodrigues Marques da Silva

um país, visto que é capaz de prover condições mínimas de bem-estar para a população.

Depois de uma longa fase marcada pelo intervencionismo estatal, em particular desde a criação das empresas estatais Chesf e Furnas na década de $1950^{4}$ e a nacionalização de empresas privadas de distribuição de eletricidade na década seguinte, mudanças institucionais importantes foram introduzidas no setor elétrico pari passu a emergência de coalizóes de orientação neoliberal, nos anos 1990 (LEME, 2009a e 2014), e social-desenvolvimentista, nos anos 2000.

A crise da dívida e da hiperinflaçáo, que levou ao ocaso do modelo desenvolvimentista no país ao final da década de 1980, teve impactos profundos na capacidade de financiamento das empresas estatais atuantes no setor elétrico brasileiro. Essas empresas chegaram à década de 1990 altamente endividadas e com problemas para financiarem suas atividades. Elas atravessavam um cenário bastante diferente do existente nas décadas de 1960 e 1970, quando foram capazes de financiar a forte expansão da geração, transmissão e distribuição de eletricidade por meio do reinvestimento dos seus lucros e da transferência de impostos e outros tributos direcionados exclusivamente para as suas atividades. $\mathrm{Na}$ década de 1980 , o governo José Sarney buscou combater a crise da dívida e o avanço da inflação por meio da adoção de planos de ajuste heterodoxo, que previam o congelamento de preços e tarifas - incluindo aí as tarifas sobre o consumo de eletricidade (PIRES, 1999; PIRES, GIAMBIAGI e SALES, 2002; LEME, 2014; SANTANA, 2015). Adicionalmente, a Constituição Federal de 1988 extinguiu o imposto único sobre energia elétrica, afetando ainda mais a capacidade de financiamento do setor (GOLDENBERG e PRADO, 2003).

Diante deste cenário, Fernando Collor, em conformidade com o conjunto de políticas neoliberais promovidas por seu governo, autorizou a liberação das tarifas e buscou socializar as dívidas do setor elétrico. Desta forma, seu governo preparava terreno para a venda das empresas estatais do setor, que foram incluídas no Plano Nacional de Desestatização, de 1993, integrando parte de um projeto maior de desmonte do intervencionismo estatal na economia brasileira. Não houve, porém, a introdução de mecanismos para regulação do mercado pós-privatizações, o que só viria a ocorrer depois dos primeiros leilóes de venda das distribuidoras federais, já no

\footnotetext{
${ }^{4}$ A criação da Eletrobras, proposta no segundo governo Getúlio Vargas, ocorreu somente na década de 1960.
} 
governo Fernando Henrique Cardoso (Ecelsa, em 1995 e Light, em 1996) (CORREIA et al., 2006).

Mesmo quando iniciadas, as privatizações no setor elétrico não avançaram no ritmo esperado pelo governo Cardoso, tendo ocorrido apenas a venda das empresas de distribuição de eletricidade, sobretudo para empresas estrangeiras 5 , e da área de geração de energia da Eletrosul, comprada pela multinacional GDF Suez em 1998 (PIRES, 1999). Interesses políticos de caráter regional - fortemente influentes na Chesf e em Furnas -, bem como a resistência da sociedade civil ao prosseguimento das privatizaçóes obstaculizaram o processo. No entanto, a atuaçáo das empresas estatais foi fortemente modificada pela reforma do setor elétrico promovida no período, que teve como pontos centrais:

- A separação funcional das atividades da indústria elétrica em geração, transmissão, distribuição e comercialização;

- A liberalização dos agentes e a criação de um mercado atacadista de energia elétrica;

- A regulação dos serviços de transmissão e distribuição, garantindo-se [sic] o livre acesso às redes de energia elétrica;

- A criação de um operador independente do sistema (ONS) e de uma agência reguladora (ANEEL) (CORREIA et al., 2006, p. 608).

A reforma institucional permitiu a abertura de capital da holding Eletrobras ${ }^{6} \mathrm{e}$ a entrada de empresas multinacionais nos diferentes segmentos do setor de eletricidade, seja pelo controle das empresas distribuidoras privatizadas, seja pela atuação direta ou em joint ventures com empresas brasileiras nos segmentos de geração e transmissão, mediante a participação em leilóes. Cabe ressaltar que a Eletrobras perdeu, na época, a prerrogativa de efetuar o planejamento da expansão setorial e do despacho de eletricidade, passando a atuar como um player no mercado, agora também povoado por empresas privadas nacionais e, principalmente, multinacionais?

\footnotetext{
${ }^{5}$ Salvo aquelas efetivamente deficitárias, que não atraíram compradores e foram mantidas sob controle do Estado.

${ }^{6}$ As empresas controladas pela Eletrobras - Furnas, Chesf, Eletrosul e Eletronorte - permanecem como empresas de capital fechado.

7 Por exemplo: Duke Energy, AES, EDF, EDP, Enel, Iberdrola e Endesa.
} 
76 | Andrea Oliveira Ribeiro e Roberta Rodrigues Marques da Silva

Tratava-se de uma reforma de orientação neoliberal, que pretendia estabelecer as regras institucionais subjacentes à regulação da competição entre agentes públicos e privados. A reforma, porém, não foi capaz de garantir a ampliação dos investimentos privados no setor, além de redundar na elevação significativa das tarifas de eletricidade, que passaram a se situar entre as mais altas do mundo (SANTANA, 2015). Não obstante a orientação neoliberal das reformas, Leme (2009a, p. 100) considera indevido o uso do termo "desregulamentaçáo" para caracterizar o processo reformista levado a cabo pelo governo Cardoso. Para o autor, as novas regulamentaçóes, mesmo que estabelecidas tardiamente, bem como o papel central do BNDES na concessão de financiamento durante as privatizaçôes (mediante o atendimento de diversos requisitos estabelecidos pelo banco), levaram à redefinição da atuação do Estado no setor elétrico, e não à sua retirada. Em outra publicação, Leme (2009b) destaca que houve a passagem de um tipo de relacionamento marcado pelo "Estado produtor" para o "Estado regulador". Sustentamos que essa passagem significou a retração do intervencionismo estatal predominante desde a década de 1950, ainda que não se possa conceber a retirada do Estado no setor elétrico.

Esta retração se expressou também na perda da capacidade de planejamento do setor. O governo Cardoso despiu as empresas estatais - com destaque para a Eletrobras - da capacidade de planejar a expansão dos investimentos, na expectativa de que o mercado fosse capaz de fazê-lo. O governo buscou transplantar, para o Brasil, um modelo estrangeiro sem considerar as especificidades da indústria de energia elétrica nacional, fortemente ancorada na geração de energia de matriz hidráulica que, entre outras características, requer investimentos de longo prazo, os quais não podem trazer o retorno imediato esperado pelos investidores privados, como ocorre em arranjos produtivos de outros países (D’ARAÚJO, 2009). De modo geral, os investimentos se concentraram em fusões e aquisiçôes, sem que ocorressem investimentos significativos de tipo greenfield.

Houve ainda retração nas políticas voltadas para a eletrificação rural em um país com parte minoritária, porém importante, da população sem acesso à eletricidade. A população excluída do acesso à eletricidade, miserável, não era considerada um potencial consumidor pelas empresas privadas, mantendo-se a sua marginalização. A inflexão em prol de uma política de eletrificação rural veio a ocorrer somente no segundo mandato de Cardoso, com a implementaçáo do Programa Luz no Campo.

As privatizações e as reformas institucionais promovidas nos anos 1990 culminaram na crise de abastecimento energético em 2001, levando o governo 
Cardoso a adotar uma política de racionamento do consumo de eletricidade. A estiagem registrada na época revelou os problemas na expansão da geração de eletricidade no Brasil (ARAÚJO, 2001). A crise do "apagão", como ficou conhecida, afetou a popularidade do presidente, que já se encontrava em declínio em razão dos resultados econômicos e sociais pífios advindos das reformas neoliberais, e contribuiu para a derrota do candidato governista José Serra em 2002, nas eleiçóes que sagraram a vitória de Lula.

Com a eleição de Lula, abriu-se espaço para a retomada de uma agenda socialdesenvolvimentista que, embora não abandonasse o tripé macroeconômico - de forma a não confrontar os interesses estabelecidos dos setores rentistas -, buscou retomar as capacidades estatais para o planejamento, a formulação de políticas industriais e a inclusão social. Essa retomada se expressou na reforma introduzida pelo governo Lula para o setor elétrico, que foi liderada por Rousseff, então Ministra de Minas e Energia. Correia et al. (2006) destacam os pontos centrais desta reforma:

- A inversão do foco dos contratos de energia elétrica do curto para o longo prazo, de modo a reduzir a volatilidade do preço e criar um mercado de contratos de longo prazo (Power Purchainsing Agremments - PPAs) que pudesse ser utilizado como garantia junto ao sistema financeiro;

- A obrigatoriedade de cobertura contratual, pelas distribuidoras e consumidores livre de $100 \%$ de seu consumo de energia elétrica;

- A instituição de mecanismos de acompanhamento das condiçóes de oferta e demanda do sistema com a criação do Comitê de Monitoramento de Setor Elétrico;

- A exigência prévia de licenças ambientais para se permitir a participação de um novo empreendimento no processo de licitação, reduzindo a possibilidade de futuras complicaçôes legais e atrasos no encaminhamento das obras, muito comuns no passado;

- A retomada do planejamento setorial integrado e centralizado pelo Estado na figura da Empresa de Pesquisa Energética (EPE) (CORREIA et al., 2006, p. 619).

${ }^{8}$ A comercialização de energia pode ocorrer em dois ambientes: (a) Ambiente de Contratação Regulada, que envolve a compra e venda de energia no longo prazo; (b) Ambiente de Contratação Livre, voltado para a negociação de contratos entre grandes consumidores e empresas concessionárias. 
78 | Andrea Oliveira Ribeiro e Roberta Rodrigues Marques da Silva

O objetivo central da reforma era retomar a capacidade estatal de planejamento da expansão da oferta de energia elétrica', estimulando os investimentos produtivos (sem oposição entre investimentos públicos e privados), ao mesmo tempo em que se buscava promover a inclusão social por meio da defesa da modicidade tarifária ${ }^{10}$ e da ampliação do programa de eletrificação rural estabelecido por Cardoso, agora denominado Luz para Todos, que pretendia universalizar o acesso à energia elétrica. A implementação desse programa também pode ser lida na chave da ampliação das capacidades estatais, no sentido de ampliação do poder infraestrutural do Estado (MANN, 1984).

A garantia da universalização do acesso à eletricidade dependia do reconhecimento de um fosso na cobertura energética do país representado pela existência de um "setor isolado" que se contrapunha ao "setor integrado" como parte do projeto de integração energética ${ }^{11}$. A revisão dos repasses devidos às empresas distribuidoras da Conta de Consumo de Combustíveis Fósseis dos Sistemas Isolados (CCC-Isol) foi um importante movimento de regulação do mercado. Como essa contribuição é cobrada de todos os consumidores do Sistema Interligado Nacional (SIN), o volume indevido de repasses, sem definição de preços, tinha impacto altista sobre toda a energia gerada, distribuída e comercializada no país. Nessa mesma direção, inclui-se a institucionalização de Leilôes de Compra de Energia (LCE), regulando o mercado futuro de energia elétrica e impedindo que as empresas fornecedoras de energia promovessem a recompra de energia produzida a preços superfaturados.

Ainda no âmbito do Plano Nacional de Energia do governo Lula (BRASIL, 2007), a alteração das finalidades do Comitê Nacional de Política Energética (CPE) ${ }^{12}$

\footnotetext{
${ }^{9}$ Por meio da retomada dos investimentos em grandes usinas hidrelétricas, como Belo Monte, Jirau e Santo Antônio.

${ }^{10}$ Que deveria ser assegurada por meio da inclusão de cláusulas de "menor tarifa" nos leilóes (CORREIA et al., 2006).

11 Sistemas isolados são aqueles que não integram do Sistema Interligado Nacional (SIN), o qual permite o acesso seguro à energia elétrica por meio do despacho de eletricidade gerada pelas usinas hidrelétricas, termelétricas, eólicas, etc. instaladas nas diversas partes do país. Embora a interconexão ao SIN tenha avançado consideravelmente desde a década de 1970 , a região amazônica e áreas do interior do país, principalmente no Nordeste, não faziam parte do sistema.

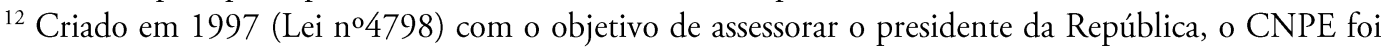
ganhando atribuiçóes ao longo de sua existência. As principais alteraçóes no que se refere ao setor

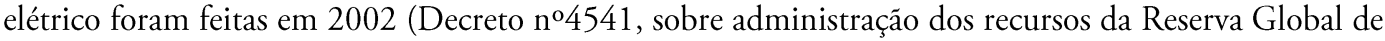
Reversão - RGR) e em 2004 (Lei no 10.848, sobre comercialização de energia elétrica).
} 
e a criação da Empresa de Pesquisa Energética (EPE) podem ser consideradas como os principais mecanismos institucionais colocados à disposiçáo do Ministério das Minas e Energia para o planejamento do setor, assumindo algumas das funções antes destinadas ao Comitê Coordenador do Planejamento da Expansão dos Sistemas Elétricos (CCPE), criado em 1999 para organizar o setor elétrico no marco do Plano Decenal 2000/2009. Os comitês técnicos do CCPE eram compostos por representantes técnicos das entidades participantes do SIN, que se revezavam na representação. Apesar de a participação estatal estar garantida, a sobre-representação das entidades privadas no processo de organização e gestão do setor elétrico colocou em xeque a isonomia do órgão.

Esperava-se que o governo Rousseff desse continuidade à política de Lula para o setor elétrico, tendo em vista que se tratava da ex-Ministra de Minas e Energia que havia liderado o processo reformista de 2003. No entanto, com sua chegada à presidência, em 2011, a trajetória institucional do setor elétrico brasileiro passa por uma nova inflexão. Atendendo às demandas apresentadas pelo empresariado industrial, em particular pela Fiesp, o governo implementou um conjunto de medidas que visava estimular o investimento privado. Foram adotadas, dentre outras medidas, a desoneração da folha de pagamento para diversos setores da indústria, a concessão de portos e aeroportos sob um novo paradigma regulatório e a redução dos preços das tarifas de eletricidade (SINGER, 2015; CARVALHO, 2018).

A redução tarifária foi viabilizada pela antecipação, para 2012, da renovação dos contratos de geração e transmissão de energia elétrica (que venceriam em 2015 e 2017), por meio da edição da Medida Provisória 579/2012 (TRIBUNAL DE CONTAS DA UNIÃO, 2014). Investimentos amortizados não foram considerados no cálculo da tarifa ${ }^{13}$, corrigindo-se uma falha existente nos contratos anteriores, que garantiam alta lucratividade para as empresas (estatais e privadas) e impediam a consecução da meta de promoção da modicidade tarifária. Com a MP 579, Dilma pretendia retomar a protagonismo estatal no setor elétrico, permitindo, ao mesmo tempo, que o Estado fosse capaz de induzir o investimento industrial e redistribuir renda, por meio do deslocamento da riqueza concentrada, gerada pelos lucros

\footnotetext{
${ }^{13}$ Uma característica dos investimentos em hidroeletricidade são os altos custos na sua fase inicial, relativos à construção dos grandes empreendimentos de geração e linhas de transmissão de longa extensão. Nos empreendimentos em que esses custos já haviam sido amortizados, o governo Rousseff se comprometeu em repassar para a tarifa somente os custos de operação e manutenção $(\mathrm{O} \& \mathrm{M})$ das usinas hidroelétricas e das redes de transmissão.
} 
extraordinários das empresas, para os consumidores (residenciais, comerciais ou industriais).

Embora a MP 579 tenha sido aprovada pelo Congresso Nacional (convertendo-se na Lei 12.783/2013), ela é amplamente aceita como um retumbante fracasso do governo Rousseff. Formulada sem o estabelecimento de consultas junto aos atores interessados - e, portanto, ignorando a importância da dimensão coordenativa para o fortalecimento das capacidades estatais -, o governo enfrentou oposição à sua implementação e, posteriormente, teve que lidar com aumentos das tarifas de eletricidade, em razáo da prolongada estiagem nos anos subsequentes à redefinição dos contratos e do pagamento de indenizaçóes, o que contribuiu para o esvaziamento do apoio popular à presidenta.

Em reação à MP 579, agentes privados - especialmente os estrangeiros - que operavam no setor elétrico e/ou detinham açóes de empresas estatais denunciaram a "insegurança jurídica" associada à medida, além de considerarem que não haveria margem de lucro suficiente para que fossem efetuados novos investimentos (SINGER, 2015). Embora fosse previsto o pagamento de indenizaçóes em contrapartida à assinatura do contrato de renovação antecipada das concessóes, não havia consenso em torno do montante a ser pago. Empresas públicas de estados governados pela oposição (CEMIG, em Minas Gerais, COPEL, no Paraná e CESP, em São Paulo $^{14}$ ) se recusaram a assinar o acordo com o governo federal. Paradoxalmente, o empresariado industrial brasileiro viria a se somar às críticas contra a retomada do intervencionismo estatal, que visava, justamente, viabilizar a retomada dos investimentos privados, em um contexto de lucratividade cadente ${ }^{15}$.

A compreensão da dinâmica que levou ao estabelecimento de uma nova reforma institucional no setor elétrico - de escopo mais limitado que os anteriores, embora com impactos profundos para as empresas - depende da análise mais ampla da disputa política que permeou o governo Rousseff, que levou a uma crise que

\footnotetext{
${ }^{14}$ A Centrais Elétricas de Santa Catarina (Celesc) também não aderiu ao programa de renovação das concessóes.

15 De acordo com relatório do Instituto Acende de maio de 2015, a MP579/2012 era responsável direta por "impor perdas ao setor elétrico", em especial aos que tinham aderido ao novo sistema. Dentre os resultados elencados, destacavam-se "redução de custos inferior ao anunciado", o "represamento tarifário" subsidiado por intervençóes do governo, a "instabilidade financeira, jurídica e institucional", e o "desequilíbrio econômico-financeiro" das empresas aderentes, configurando o processo de implementação como "atabalhoado" e "pouco transparente" (INSTITUTO ACENDE, 2015).
} 
chegou ao ápice no seu segundo mandato. Na próxima seção, nos voltamos para essa discussão.

\section{Governo Dilma: ruina da coalizão desenvolvimentista}

Em 2011, ano que Dilma assume o poder, o contexto internacional positivo que havia permitido ao seu antecessor promover um giro na condução da política econômica e avançar no projeto de inclusão social e financeira, já não existia. Após a crise de 2008, um novo ciclo de reordenamento econômico teve início, redirecionando os fluxos de capital internacional e comprometendo o equilíbrio da balança de pagamentos (CARVALHO, 2018). A despeito da situação internacional adversa, o governo recém empossado implementou uma agenda ativa de crescimento com a retomada dos investimentos públicos em infraestrutura, a tentativa de disciplinar o capital financeiro, e o aprofundamento da política de inclusão social via emprego. Contudo, essas iniciativas não foram suficientes para evitar o esfacelamento da coalizão de apoio ao governo e a posterior destituição de Dilma. Dentre os fatores que explicam a erosão do suporte à presidência, estão a dificuldade de recuperar os ritmos de crescimento; a deterioração da capacidade fiscal do Estado; além da crescente insatisfação popular epitomizada pelas manifestações de 2013, associadas à percepção de corrupção no meio político.

Não há consenso na literatura sobre o aprofundamento da agenda desenvolvimentista por parte do governo Dilma Rousseff. Singer (2015) defende que houve uma tentativa de radicalizar o caráter desenvolvimentista do governo Lula ao buscar repactuar os termos de contrato da coalizão de apoio ao governo, em busca de garantir a retomada do investimento produtivo, ou de estabelecer uma coalizão de investimento (PINHO, 2017). Essa tese se apoia nos resultados dos conflitos em torno do controle de capitais (imposição de IOF às transaçôes internacionais), nas imposições ao setor financeiro via redução de spreads bancários e na tentativa de repactuar os contratos de concessão das empresas de geração e transmissão de energia elétrica (SILVA e RIBEIRO, 2017).

Por outro lado, há ainda uma literatura que ressalta os erros políticos e econômicos, atribuídos à persona da presidenta, que teriam levado à perda de sua legitimidade como mandatária (CARVALHO, 2018). De forma distinta, Bastos (2017) afirma que a tentativa de "eliminar o rentismo" foi precedida por um sinal equivocado dado pelo governo ao nomear Joaquim Levy, executivo oriundo do Bradesco, para o Ministério da Fazenda, e pela incapacidade de criar um 
contradiscurso à hegemonia do poder estrutural do capital financeiro. Essa inflexão teria corrompido o pacto de poder existente durante os anos de governo Lula, que contentava os principais grupos de apoio ligados ao capital (industriais, agropecuaristas, financistas) enquanto fazia concessões às bases de apoio popular. Em 2015, a ruptura da coalizão político-partidária que permitiu a reeleição de Rousseff se torna evidente, instaurando a crise orgânica que culminaria com a deposição da presidenta em agosto de 2016. O afastamento de Rousseff criou o espaço para que uma coalizão de interesses não legitimada pelo voto popular implementasse uma agenda política diametralmente oposta ao projeto de desenvolvimento com inclusão social instaurado em 2003.

Como uma das primeiras medidas do governo Temer, determinou-se o congelamento de gastos durante 20 anos (Emenda Constitucional 95, de 15/12/2016), impedindo a ampliação do gasto público social. Além disso, o governo interino procurou avançar na Reforma da Previdência (PEC 287 e 287-A, de 2017), sem sucesso, e retomar o Programa Nacional de Desestatização de 1997, sob novo rótulo, Programa de Parcerias de Investimento (PPI), lançado em 2016 (Lei 13.334). Todas as iniciativas estavam contidas no programa partidário do MDB (antigo PMDB) Ponte para o Futuro (FUNDAÇÃO ULYSSES GUIMARÃES, 2015), que preconizava o projeto de austeridade do governo interino.

Uma série de fatores (políticos, econômicos e sociais, domésticos e internacionais) devem ser considerados na explicação do por que o governo Dilma caiu em 2016. Fatores que tiveram impacto direto nas capacidades do Estado brasileiro de implementar o projeto político do governo de forma autônoma ou consensuada. Embora não seja o nosso objetivo exaurir o debate sobre esses fatores, destacamos aqueles que mais diretamente afetaram a tramitação da MP579/2012 e que nos ajudam a caracterizar o conflito entre os atores envolvidos no imbróglio em torno da definição de um novo regime regulatório para o setor de energia elétrica.

$\mathrm{Na}$ arena parlamentar, destaca-se a transformação do comportamento do PMDB como partido da base aliada. A aliança PT-PMDB foi oficializada para permitir a candidatura de Rousseff em 2010, mas acabou sendo rompida com a articulação de uma coalizão parlamentar de oposição de facto a partir da eleição de Eduardo Cunha (PMDB-RJ) para a presidência da Câmara dos Deputados, no começo de 2015. O distanciamento da presidenta de sua base aliada, a partir de 2013, havia produzido paulatinamente a paralisia governamental, que ficaria evidente logo após a reeleição, quando Cunha passou a decidir a pauta de votação e obstaculizar a agenda do governo. Os principais entraves tinham relação com a 
aprovação do Código Florestal e a MP dos Portos. Em dezembro de 2015, Cunha desafiou abertamente a autoridade de Rousseff, ao ameaçar protocolar os pedidos de impeachment sob sua responsabilidade e organizar um bloco parlamentar contra a aprovação das medidas econômicas propostas pelo governo, evento que definiu a cisão político-partidária. A tramitação em urgência da MP579/2012 ${ }^{16}$ foi anterior à cisão da base aliada. Sua aprovação foi garantida com o apoio do vice-presidente e dos relatores: senador Renan Calheiros (PMDB-AL) e deputado Eduardo Cunha (PMDB-RJ). Apesar da aprovação expressa, empresas do setor energético, através da Associação Brasileira de Distribuidores de Energia Elétrica (ABRADEE) e da Associação Brasileira das Empresas de Transmissão de Energia Elétrica (ABRATE), dentre outras, passaram a pressionar o governo a fazer alteraçôes na proposta original. Simultaneamente, uma campanha midiática atacava a decisão governamental de implementar o novo marco regulatório, que imporia a comercialização de energia no mercado regulado e resultaria em perdas no valor de mercado das empresas energéticas.

Ainda antes da aprovação da medida, Rousseff fez críticas abertas às empresas que não queriam aderir ao novo regime, as quais chamou de "não-colaboradores" (PERES, 2012). Para resolver o problema das indenizaçóes e permitir maior adesão das concessionárias (que havia chegado a apenas $60 \%$ do volume previsto), em especial as transmissoras de energia, entrou em vigor em novembro a MP591/2012, que definia um prazo de 30 anos para indenizaçóes com correção pelo Índice de Preços ao Consumidor (IPCA). A insatisfação dos agentes privados com o regime de indenizações e as perdas impostas pelo quadro de estiagem e encarecimento da energia ao longo de 2012/2013, forçaram o governo a intervir por meio de aportes à Conta de Desenvolvimento Energético (Decreto nº7945/2013) e pela realização de Leilóes de Energia Existente (LEE, no 11 e 12), com resultados insatisfatórios. No primeiro leilão não houve negociação e, no segundo, o volume negociado não correspondia à necessidade das distribuidoras (COSTELLINI e HOLLANDA, 2014).

O setor privado era também o maior crítico aos preços altos da energia elétrica que impediam o maior dinamismo industrial, sendo, portanto, um dos supostos beneficiários do novo marco regulatório. A bandeira da modicidade tarifária

\footnotetext{
${ }^{16}$ A MP579 foi publicada em 12 de setembro e aprovada pela Câmara dos Deputados e encaminhada ao Senado em 18 de dezembro, depois de apresentadas 431 propostas de emendas.
} 
84 | Andrea Oliveira Ribeiro e Roberta Rodrigues Marques da Silva

poderia agradar aos consumidores de classe média, residenciais, e aos industriais, mas as perdas impostas ao setor com os vários ciclos de reversão tarifária e o ambiente de imprevisibilidade podem ser contabilizados como um elemento fundamental para entender o conflito interno que ruiu a base de apoio ao governo. As empresas que não aderiram ao novo regime e preferiram negociar no mercado livre forçaram a alta de preços da energia, impactando negativamente as distribuidoras que decidiram operar no mercado regulado e foram obrigadas a comprar no mercado livre para suprir a demanda. O custo da "exposição involuntária" a que foram submetidas as empresas distribuidoras recaiu sobre o governo. Segundo o Tribunal de Contas da Uniáo, no biênio 2013/2014, as despesas governamentais com a CDE chegaram a cerca de $\mathrm{R} \$ 61$ bilhões; enquanto a reestruturação tarifária teria proporcionado uma economia anual de $\mathrm{R} \$ 16,8$ bilhões. Além disso, as negociações do governo e suas sucessivas intervençôes configuraram-se como medidas pontuais, destinadas à resolução de problemas conjunturais que teriam impacto sobre as tarifas ao consumidor final praticadas até 2014, sem resolver o problema estrutural da composição tarifária.

O conflito em torno do novo marco regulatório do setor energético ocorre no contexto de redefinição da política macroeconômica para enfrentar a crise financeira internacional, a Nova Matriz Econômica (NME). Apoiada no alinhamento entre o Ministério da Fazenda e o Bacen, a NME se traduziu em um conjunto de políticas pró cíclicas cujo objetivo era retomar os níveis de investimento e produtividade da indústria nacional por meio da concessão de subsídios (PAC2, Programa Brasil Maior) e controle cambial e de capitais. A tentativa de flexibilizar o tripé macroeconômico e, portanto, estabelecer um regime de administração antiausteridade ruiu ainda no primeiro governo, abrindo confronto com o setor financeiro (RIBEIRO, 2018). Após a reeleição, Dilma deu a guinada em direção à austeridade, simbolizada pela indicação de Levy para o Ministério da Fazenda. Como primeira função, o novo ministro elaborou um plano de recuperação econômica com ajuste fiscal que não gerou os resultados esperados: nem a inflaçáo desacelerou, nem a produtividade aumentou. As previsóes de crescimento do PIB passaram a indicar uma situação de "recessão técnica" e após um crescimento pífio de 0,5\% em 2014, houve crescimento negativo nos anos de 2015 e 2016 (-3,8\% e -3,5\%, respectivamente) (BACEN, 2018).

O quadro de retração econômica teve impacto direto sobre os índices de produção industrial. Desde 2010, a taxa de investimento vinha caindo e, a partir do segundo trimestre de 2014, passou a apresentar números negativos (de $-6,33 \%$, para $12,5 \%$ no segundo trimestre de 2015 , a $-17,3 \%$ no terceiro trimestre de 2016) 
(IPEA, 2019). A dificuldade de recuperação da indústria pode explicar a "saída" (HIRSCHMAN, 1973) desse grupo da coalizão governista. A insatisfação do setor industrial já era pública desde 2013, quando a Fiesp apresentou seu "projeto alternativo" para o país, criticando abertamente a política de valorização do salário mínimo e os programas de transferência de renda como mecanismos "distorcivos" que já haviam "cumprido o seu papel”, ao lado dos subsídios governamentais destinados à própria indústria (FIESP, 2013).

Para concluir, indicamos que a ruína da coalizão partidária ampla de apoio ao governo foi determinada pela deterioração das relaçóes entre o Executivo e o Legislativo, e entre o governo e o setor privado e culminou com a destituição de Rousseff, em 2016. Não propomos que o embate travado em torno do novo marco regulatório é o único elemento explicativo, mas sugerimos que é um dos mais relevantes na composição desse quadro de crises (econômica, institucional, e de hegemonia do discurso governamental de crescimento com inclusão social).

A transformação das condiçôes econômicas internacionais pós-crise de 2008 representou um grande desafio à estratégia de desenvolvimento brasileira no plano global. Não obstante a crise internacional, somou-se a movimentação dos atores políticos no cenário doméstico, na busca por renegociar os espólios da guerra financeira. A interdependência econômica, que estreitou a margem de manobra doméstica ao reduzir o campo de flexibilidade fiscal, contribuiu para reduzir o campo de ação da presidenta. Por outro lado, um aspecto constituinte e estrutural do sistema político brasileiro, e que deixou às claras os limites de projetos de inclusão social num país tradicionalmente desigual, permitiu que a crise se estabelecesse como uma crise nacional, e não uma crise dos setores com poder econômico lutando entre si. Nesse cenário, o PMDB, demonstrou seu caráter plástico e sua força política e capacidade de repor e ressignificar a agenda política conservadora.

\section{Considerações Finais}

Este trabalho tem caráter exploratório e busca levantar algumas explicações para a melhor compreensão do conflito político-distributivo por trás da queda de Dilma em 2016. Optamos por examinar o caso da crise do setor elétrico e a tentativa de redefiniçáo do marco regulatório para o mercado de energia elétrica. Nesse sentido, as agências e órgãos estatais envolvidos na formulação e fiscalização de políticas para o setor têm um papel fundamental na explicação sobre as capacidades estatais e na coordenação das mesmas. Mas os agentes políticos que operam nesse 
86 | Andrea Oliveira Ribeiro e Roberta Rodrigues Marques da Silva

jogo (técnicos, parlamentares, empresários) têm não apenas distintos interesses, mas diferentes percepçóes e modos de entender seu papel quando se trata de fatiar e repartir os lucros auferidos. Embora o governo Dilma tenha buscado repactuar com os grupos privados envolvidos na geração e transmissão de energia, não logrou manter-se no poder com o apoio desses mesmos grupos.

Defendemos que essa diferença de interesses e percepções, não processada satisfatoriamente no âmbito das instituiçôes, pode explicar os conflitos enfrentados pelo Executivo. Ela tem impacto significativo na capacidade de coordenação entre agências e órgáos, isto é, o conflito afeta o grau com que o governo consegue implementar sua agenda. Maior comunicação e produção de consenso interno às agências e órgãos deve produzir maior eficácia quando o governo decide mudar de rumo. Retomando Pires e Gomide (2016), havia relativa capacidade técnicaadministrativa disponível, com mecanismos escassos de "estratégias de produção de informação e exigências de desempenho", além de coordenação falha intra e intergovernamental. Sobretudo, negligenciaram-se as capacidades do tipo políticorelacional: onde dominou a carência de transparência e participação social, que poderiam fortalecer os laços de comprometimento dos setores envolvidos nas reformas, e intensificou-se a ideia de que o governo empreendia uma reforma arbitrária e sem sentido.

Andrea Oliveira Ribeiro é Pesquisadora Pós-doutorado (PNPD/CAPES) do Programa de Pós-graduação em Ciência Política da Universidade Federal Fluminense (PPGCP/UFF) e Pesquisadora do INCT/PPED. E-mail: aoribeiro@gmail.com.

- Roberta Rodrigues Marques da Silva é Doutora em Ciência Politica pela Universidade Estadual do Rio de Janeiro. Professora Adjunta do Departamento de Ciência Politica da Universidade Federal Fluminense e pesquisadora do INCT/PPED. E-mail: robertarodrigues@id.uff.br. 


\section{Referências}

ARAÚJO, João Lizandro. A questão do investimento no setor elétrico brasileiro: reforma e crise. Nova Economia, v. 11, n. 01, p. 77-96, 2001.

BANCO CENTRAL DO BRASIL (BACEN). Sistema Gerador de Séries Temporais. Brasília (Brasil). 1962-. 2018. Disponível em:

$<$ https://www3.bcb.gov.br/sgspub/localizarseries/localizarSeries.do?method=prepararTelaLocalizarSer ies>. Acesso em: 10 jun. 2019.

BASTOS, Pedro Paulo. Ascensão e crise do governo Dilma Rousseff e o golpe de 2016: poder estrutural, contradição e ideologia. Rev. Econ. Contemp., núm. esp., p. 1-63, 2017.

BRASIL. Empresa de Pesquisa Energética. Plano Nacional de Energia 2030. Rio de Janeiro: EPE, 2007.

CARVALHO, Laura. Valsa brasileira: do boom ao caos econômico. São Paulo: Todavia, 2018.

CENTENO, Miguel; KOHLI, Atul; YASHAR, Deborah. States in the developing world. Cambridge: Cambridge University Press, 2017.

CORREIA, Tiago; MELO, Elbia; COSTA, Agnes; SILVA, Adriano. Trajetória das reformas da indústria elétrica brasileira e novas perspectivas para de mercado. Revista Economia, v. 7, n. 3, p. 607-627, 2006.

COSTELLINI, Clara; HOLLANDA, Lavínia. Setor elétrico: da MP579 ao pacote financeiro. Informativo de Energia, FGV Energia, 31 mar. 2014.

EVANS, Peter. Embedded Autonomy: States and Industrial Transformation. Princeton University, 1995.

EVANS, Peter; RUESCHEMEYER, Dietrich; SKOCPOL, Theda (Eds.). Bringing the state back in. New York: Cambridge University Press, 1985.

D’ARAÚJO, Roberto. Setor elétrico brasileiro: uma aventura mercantil. Brasília: CONFEA, 2009.

FEDERAÇÃO DAS INDÚSTRIAS DO ESTADO DE SÃP PAULO (FIESP). Estratégia de Potencial Socioeconômico Pleno para o Brasil. Portal Fiesp, set. 2013. Disponível em: $<$ http://www.fiesp.com.br/indices-pesquisas-e-publicacoes/estrategia-de-potencial-socioeconomicopleno-para-o-brasil/>. Acesso em: 10 out. 2018.

FUNDAÇÃO ULYSSES GUIMARÃES. Uma ponte para o futuro. Brasília, 29 out. 2015.

GOLDENBERG, José; PRADO, Luiz Tadeu. Reforma e crise do setor elétrico no período FHC. Tempo Social, v.15, n.02, p. 219-235, 2003.

GOMIDE, Alexandre. Capacidades estatais para políticas públicas em países emergentes: (des)vantagens comparativas do Brasil. In: GOMIDE, Alexandre; BOSCHI, Renato (Orgs.).

Capacidades estatais em países emergentes: o Brasil em perspectiva comparada. Brasília, Ipea, 2016, p. $15-48$.

GOMIDE, Alexandre; PIRES, Roberto. Capacidades estatais e democracia: a abordagem dos arranjos institucionais para análise de políticas públicas. Brasília: Ipea, 2014.

HIRSCHMAN, Albert. Saída, voz e lealdade. São Paulo: Perspectiva, 1973.

INSTITUTO ACENDE. Os impactos da MP579/2012: a utlização da CDE e a perda de sustentabilidade do setor elétrico brasileiro. Maio 2015. Disponível em:

<http://www.acendebrasil.com.br/media/eventos/InstitutoAcendeBrasil_CDE_Perdadesustentabilida dedosetoreletrico_rev1.pdf>. Acesso em: 03 maio 2019. 
INSTITUTO DE PESQUISA E ECONÔMICA APLICADA (IPEA). Investimento Real, Séries Históricas. Atual. 25 maio 2019. Disponível em: <http://www.ipeadata.gov.br/ExibeSerie.aspx?serid=38406>. Acesso em: 03 jun. 2019.

JOBERT, Bruno, MULLER, Pierre. L'Etat en action, politiques publiques et corporatismes. Paris: Presses Universitaires de France, 1987.

LEME, Alessandro. O setor elétrico entre a questão histórica e os problemas sociológicos. Ciências Sociais Unisinos, v. 50, n. 2, p. 166-176, 2014.

LEME, Alessandro. Reforma do setor elétrico no Brasil, Argentina e México: contrastes e perspectivas em debate. Revista de Sociologia e Política, v. 17, n.33, p. 97-121, 2009a.

LEME, Alessandro. Estado e reformas orientadas para o mercado: compassos e (des)compassos na reestruturação do setor elétrico brasileiro na década de 1990. Teoria \& Pesquisa, v. 18, n. 2, p. $182-$ 196, 2009b.

MARQUES, Eduardo. As políticas públicas na ciência política. In: MARQUES, Eduardo; PIMENTA DE FARIA, Carlos Aurélio. A política pública como campo multidisciplinar. São Paulo: Unesp, 2013

MANN, Michael. The autonomous power of the state: its origins, mechanisms and results. European Journal of Sociology/Archives européennes de sociologie, v. 25, n. 2, p. 185-213, 1984.

PERES, Bruno. Temer reúne PMDB para aprovar MP das elétricas no Congresso. Valor Econômico Online, 10 dez. 2012. Disponível em: <https://www.valor.com.br/politica/2934280/temer-reunepmdb-para-aprovar-mp-das-eletricas-no-congresso>. Acesso em: 03 abr. 2019.

PINHO, Carlos Eduardo. Ascensão e Ocaso do Governo Dilma Rousseff à Luz das Capacidades do Estado Brasileiro: usurpação democrática e corrosão do Estado do Bem-Estar Social (2011-2016). In: CARDOSO JR, José Celso (Org.). Planejamento Governamental e Finanças Públicas no Brasil Contemporâneo: perspectivas críticas ao financiamento do desenvolvimento no séc. XXI. São Paulo: HUCITEC, 2017. v. 2. p. 120-168.

PIRES, José Cláudio. O processo de reformas do setor elétrico brasileiro. Revista do BNDES, v. 6, n. 12, p. 137-168, 1999.

PIRES, José Cláudio; GIAMBIAGI, Fábio; SALES, André. As perspectivas do setor elétrico após o racionamento. Revista do BNDES, v. 9, n. 18, p. 163-204, 2002.

PIRES, Roberto; GOMIDE, Alexandre. Governança e capacidades estatais: uma análise comparativa de programas federais. Revista de Sociologia e Política, v. 24, n. 58, p. 121-143, 2016.

RIBEIRO, Andrea. Desenvolvimento e coalizóes no pós-neoliberalismo: os casos do Brasil e da Argentina (2003-2014). 2018. 294 f. Tese (Doutorado em Ciência Política) - Programa de PósGraduação em Ciência Política, Instituto de Estudos Sociais e Políticos, Universidade do Estado do Rio de Janeiro (UERJ), Rio de Janeiro, 2018.

SANTANA, Carlos Henrique. Políticas de infraestrutura energética e capacidades estatais no BRICS. Texto para Discussão 2045. Rio de Janeiro: Ipea, 2015.

SILVA, Roberta Rodrigues; RIBEIRO, Andrea O. Marco regulatório do setor elétrico e coalizóes de apoio ao governo Dilma: capacidades de coordenação, interesses privados e crise. In: ALACIP - IX Congreso Latinoamericano de Ciencia Política, Montevideo, 2017.

SINGER, André. Cutucando onças com varas curtas: o ensaio desenvolvimentista no primeiro mandato de Dilma Rousseff (2011-2014). Novos Estudos CEBRAP, n. 102, p. 39-67, jul. 2015. 
SKOCPOL, Theda. Bringing the state back in: strategies of analysis in current research. In: EVANS, Peter; RUESCHEMEYER, Dietrich; SKOCPOL, Theda (Eds.). Bringing the state back in. New York: Cambridge University Press, 1985. p.03-37.

SOUZA, Celina. Políticas públicas: uma revisão da literatura. Sociologias, n. 16, p. 20-45, dez. 2006. Disponível em: <http://www.scielo.br/scielo.php?script=sci_arttext\&pid=S1517$45222006000200003 \& \operatorname{lng}=\mathrm{en} \& \mathrm{nrm}=\mathrm{iso}>$. Acesso em: 30 abr. 2019.

TILLY, Charles. Coerção, capital e Estados europeus 1990-1992. São Paulo: Edusp, 1996.

TRIBUNAL DE CONTAS DA UNIÃO. Impactos da Medida Provisória 579/2012 sobre a Conta de Desenvolvimento Energético. Out. 2014. Disponível em: <https://portal.tcu.gov.br/bibliotecadigital/impactos-da-medida-provisoria-579-2012-sobre-a-conta-de-desenvolvimento-energeticocde.htm>. Acesso em: 30 abr. 2019.

Texto recebido em 17 de dezembro de 2018. Aprovado em 25 de abril de 2019. 